\title{
Resistin Levels and Inflammatory and Endothelial Dysfunction Markers in Obese Postmenopausal Women With Type 2 Diabetes Mellitus.
}

\section{Annalisa GIANDALIA ( $\sim$ agiandalia@yahoo.it )}

University of Messina: Universita degli Studi di Messina

Angela Alibrandi

University of Messina: Universita degli Studi di Messina

Letterio Giorgianni

University of Messina: Universita degli Studi di Messina

\section{Federico Lo Piano}

University of Messina: Universita degli Studi di Messina

Francesca Consolo

University of Messina: Universita degli Studi di Messina

\section{Giorgio Elia Longo}

University of Messina: Universita degli Studi di Messina

\section{Bela Asztalos}

Tufts University

\section{Domenico Cucinotta}

University of Messina: Universita degli Studi di Messina

\section{Giovanni Squadrito}

University of Messina: Universita degli Studi di Messina

\section{Giuseppina Russo}

University of Messina: Universita degli Studi di Messina

\section{Research}

Keywords: Resistin, inflammation, women, type 2 diabetes, CHD

Posted Date: July 6th, 2021

DOl: https://doi.org/10.21203/rs.3.rs-591959/v1

License: (c) (1) This work is licensed under a Creative Commons Attribution 4.0 International License.

Read Full License 


\section{Abstract}

Background: Obesity- associated coronary heart disease (CHD) risk is higher in women than in men with type 2 diabetes (T2DM). Resistin, an adipokine secreted by adispose tissue, may contribute to this higher risk.

Aims: To explore the relationships among resistin levels and common inflammatory and endothelial dysfunction markers and CHD risk in obese post-menopausal T2DM women.

Methods: Serum levels of resistin, hsCRP, IL-6, Soluble vascular cell adhesion molecule (sVCAM), homocysteine (tHcy), HOMA-IR and metabolic parameters were determined in a group of 132 T2DM women with and without documented CHD and in 55 non-diabetic women.

Results: Resistin, sVCAM, IL-6 and tHcy levels were comparable in T2DM and controls. CHD women showed higher resistin, SVCAM and tHcy levels than those without $\mathrm{CHD}$, and for resistin this difference remained significant after age-adjustment $(P=0.013)$; conversely hsCRP were $\sim 2 \mathrm{X}$ higher in T2DM women than in controls $(P=0.0132)$ without any difference according to $C H D$ history.

At univariate analysis resistin levels were significantly associated with age, waist circumference, hypertension, tHcy, hsPCR, sVCAM, IL-6, HDL-cholesterol, triglycerides and creatinine levels, but only creatinine, triglycerides, hSCRP, IL- 6 and SVCAM were independent predictors of resistin levels at stepwise regression analysis.

Resistin levels were independent predictors of CHD, increasing the risk by 1.15 times $(0.986-1.34495 \%$ $\mathrm{Cl}$ ), together with age, tHcy, LDL-C and hypertension.

Conclusions: Circulating resistin levels were comparable in obese/overweight T2DM and control women. In T2DM women, resistin levels correlated with markers of renal function, systemic inflammation and endothelial dysfunction and were independently associated with a higher CHD risk.

\section{Background}

Type 2 diabetes mellitus (T2DM) is a chronic and progressive disease characterized by insulin resistance and different degrees of beta cell dysfunction (1). Cardiovascular disease (CVD) is the leading cause of death in T2DM subjects, especially in women, who lose the estrogenic protection and are exposed to the risk of major CVD events even at younger ages $(2,3)$.

The pathophysiological basis of the excessive CVD risk in T2DM women is still partly unknown, although several lines of evidence point to a different burden of classical and non-classical CVD risk factors in the two genders (4-7).

Among these, obesity has been demonstrated to confer a higher CVD risk in women than in men with T2DM (8-10). 
In addition to its role in energy storage and metabolic balance, adipose tissue is an active endocrine organ releasing several factors involved in systemic inflammation, insulin-resistance and CVD risk, including resistin $(11,12)$.

Resistin is an adipokine discovered in 2001 as a thiazolidinedione-downregulated gene in mouse adipocytes (13). In rodents, circulating levels of resistin are increased in obesity, and have been demonstrated to play a role in mediating hepatic and skeletal muscle insulin resistance and in the regulation of glucose metabolism through AMP activation (14-19).

While its role seems to be well defined in animal models, there is considerable controversy on the pathophysiological role of resistin in humans.

Indeed, blood circulating levels of resistin have been shown to be increased in subjects with insulin resistance, T2DM, metabolic syndrome, hypertension and overt CVD (20-23), while other Authors failed to show any significant relationship (24-27).

Furthermore, experimental studies have pointed to the role of resistin in the inflammatory process: the expression of resistin in human peripheral-blood mononuclear cells is upregulated by the proinflammatory cytokines tumor necrosis factor-a (TNF-a) and interleukin-6 (IL-6), and resistin induced the expression of these molecules in white adipose tissue and in peripheral-blood mononuclear cells (13, 28).

The divergent results reported in literature on the role of resistin in human pathophysiology may depend on several factors, spanning from biological aspects to the specific study design and studied population characteristics, also including potential sex/gender-differences. As for obesity (8-10, 29), a different impact of several risk factors in micro- and macrovascular complications has been reported in T2DM men and women $(30,31)$, and gender-related differences in the association of plasma levels of resistin with anthropometric parameters were also observed (32).

\section{Aim}

Because of the high obesity-related CHD risk in T2DM women, the aim of this study was to explore the relationship between resistin levels and major risk factors, including inflammatory and endothelial dysfunction markers, in overweight/obese T2DM, with and without established CHD, and in a group of women without T2DM.

\section{Methods}

\subsection{Study population}

A group of T2DM women with ( $n=36 ; 27 \%)$ and without $(n=96,73 \%)$ documented coronary heart disease $(\mathrm{CHD})$ and a group of non-diabetic women $(n=55)$ were consecutively recruited at their first visit among 
those attending the metabolic disease outpatient clinic of Messina University Hospital and from voluntary employees of the same Institution. Inclusion criteria for both diabetic and control women were a BMI value $\geq 25 \mathrm{~kg} / \mathrm{m}^{2}$ and being post-menopausal. Menopausal status was defined as amenorrhea for at least 12 months before the study entry or hysterectomy, considering the date of surgery as the beginning of menopause. T2DM was diagnosed according to ADA criteria (33). All T2DM subjects were on dietary therapy, oral hypoglycemic agents, insulin or a combination between them.

Exclusion criteria for all participants were pregnancy, current treatment with glucosorticoids, inflammatory drugs and thiazolidinediones, hormonal replacement therapy, oral contraceptive use or multivitamin supplementation; cancer or any major medical condition in the last 6 months preceding the study.

Hypertension was defined according to current guidelines (34).

All the participants gave their informed consent and the local ethical committee approved the study.

\subsection{Measurements of laboratory parameters}

At the enrollment visit, all participants underwent a clinical questionnaire, a complete physical examination and fasting blood sampling for the measurement of study parameters. Anthropometric parameters and blood pressure were measured according to standard procedures.

After a 12-14-h fasting, blood samples were collected from all participants for the determination of the study parameters. Blood was drown in a $10-\mathrm{mL}$ tube containing EDTA ( $0.15 \%$ final concentration) and in a regular $10-\mathrm{mL}$ tube. After collection, plasma and serum were immediately separated at $2500 \mathrm{rpm}$ for 30 min at $4 \circ \mathrm{C}$, and aliquots were stored at $-80^{\circ} \mathrm{C}$ until analysis.

Fasting plasma glucose and serum creatinine levels were measured with standard automated laboratory methods (Roche Diagnostics, Milan, Italy). Glycated haemoglobin (HbA1c) was measured using an automated high-performance liquid chromatography (HPLC) analyzer (Diamat; Bio-Rad Laboratories, Milan, Italy); normal range values in our laboratory are 4-6\%. Fasting insulin concentration was measured by radioimmunoassay (Diagnostic Corporation, LA, CA). Insulin resistance was calculated by the homeostasis model assessment (HOMA-IR) [16 ref].

Plasma total cholesterol and triglycerides levels were measured by automated enzymatic assays. HDL-C was measured directly with a kit from Roche Diagnostics (Indianapolis, IN). Plasma total cholesterol and triglycerides levels were measured by automated enzymatic assays [ref]. Direct low-density lipoprotein cholesterol (LDL-C) was measured with reagents from Equal Diagnostics (Exton, PA). HDL cholesterol (HDL-C) was measured directly with a kit from Roche Diagnostics (Indianapolis, IN).

Glomerular filtration rate (GFR) was estimated by using CKD EPI equation (35).

\subsection{Measurements of Resistin, inflammatory and endothelial dysfunction markers}


Serum levels of resistin, IL-6 and VCAM-1 were determined by ELISA (R\&D Systems, Minneapolis, Minnesota); hsCRP were assayed with a high-sensitivity test (Dade Behring Inc., Deerfield, Illinois); tHcy plasma concentration was measured with HPLC technique (Bio- Rad Laboratories, Milan, Italy; CV 2.9 \%).

\subsection{Assessment of T2DM micro- and macrovascular complications}

Diabetic micro-and macroangiopathy were screened according to national and international diabetes guidelines $(34,36)$.

Diabetic retinopathy was diagnosed based on direct ophthalmoscopy (through a dilated pupil) performed by an expert ophthalmologist and/or by fluorescein angiography within 1 year before the start of study.

Diabetic kidney disease was diagnosed according to estimated Glomerular Filtration Rate (eGFR estimated by CKD EPI) and albuminuria measurements, as the presence of impaired eGFR < $60 \mathrm{ml} / \mathrm{min} / 1.73 \mathrm{~m}^{2}$ and/or albuminuria $\geq 30 \mathrm{mg} / \mathrm{die}$.

Coronary heart disease (CHD) was defined as a history of myocardial infarction, chronic ischemic heart disease, coronary heart by-pass, coronary angioplasty, documented by cardiologist

medical records and/or hospital discharge. Asymptomatic myocardial infarction or arrhythmia were excluded on the basis of a standard electrocardiogram and cardiologist visit, performed annually in all T2DM patients as part of the usual screening program.

Cerebrovascular disease or peripheral arterial disease were assessed by color-doppler ultrasonography by B-mode real-time ultrasound, as part of the periodic screening of macrovascular complications.

\subsection{Statistical Analyses}

Statistical analysis was performed using the SPSS program, version 11.0 for Windows (SPSS Inc. Chicago, IL). Data are expressed as mean \pm SD; most of examined variables were normally distributed as verified by Kolmogorov-Smirnov test; consequently, the parametric approach has been used. We used $\chi 2$ test to compare categorical measures, and the analysis of variance (ANOVA) for continuous measures. For each parameter, we performed statistical comparisons between groups applying Student's $t$-test.

Linear regression models were determined using a stepwise selection procedure in order to assess the possible dependence of resistin on study variables; firstly, we estimated all univariate models; subsequently, a stepwise multivariate regression analysis was performed. All statistical comparisons are two-tailed; a value of $P<0.05$ was considered to be statistically significant.

\section{Results}

\section{Clinical characteristics of T2DM and control women participating to the study}


Demographic and clinical characteristics of the overweight/obese postmenopausal women (132 T2DM women and 55 controls women; mean age 59 yrs and $57 \mathrm{yrs}$, respectively; $\mathrm{P}=0.265$ ) participating to the study are shown in Table 1. 
Table 1

- Clinical characteristics of T2DM and control women participating to the study.

\begin{tabular}{|llll|}
\hline & T2DM & Control & P \\
\hline $\mathrm{n}$ & women & women & \\
\hline Age (years) & 132 & 55 & \\
\hline BMI (Kg/m2) & $59.04 \pm 12.61$ & $57.0 \pm 7.45$ & 0.265 \\
\hline Waist circumference (cm) & $31.74 \pm 5.94$ & $28.38 \pm 4.52$ & $<0.001$ \\
\hline Smokers n (\%) & $100.03 \pm 11.61$ & $90.73 \pm 14.87$ & 0.0006 \\
\hline Systolic Blood Pressure (mmHg) & $134.39 \pm 17.35$ & $125.46 \pm 12.75$ & 0.0008 \\
\hline Diastolic Blood Pressure (mmHg) & $78.52 \pm 9.09$ & $73.15 \pm 9.38$ & 0.0003 \\
\hline Diabetes duration (years) & $7.77 \pm 8.97$ & - & - \\
\hline HbA1c (\%) & $7.44 \pm 1.44$ & - & - \\
\hline Fasting plasma glucose (mg/dl) & $161.99 \pm 50.03$ & $96.75 \pm 5.98$ & $<0.001$ \\
\hline Insulin (mU/L) & $16.38 \pm 10.80$ & $13.82 \pm 10.11$ & 0.68 \\
\hline HOMA-IR & $6.86 \pm 5.72$ & $3.32 \pm 2.46$ & 0.0007 \\
\hline Creatinine (mg/dl) & $0.89 \pm 0.20$ & $0.85 \pm 0.10$ & 0.114 \\
\hline eGFR (ml/min/1.73 m $\left.{ }^{2}\right)$ & $68.27 \pm 14.71$ & $70.66 \pm 10.32$ & 0.273 \\
\hline Total cholesterol (mg/dl) & $186.74 \pm 29.64$ & $201.00 \pm 28.26$ & 0.0016 \\
\hline HDL-cholesterol (mg/dl) & $48.19 \pm 13.69$ & $53.76 \pm 12.43$ & 0.010 \\
\hline Triglycerides (mg/dl) & $121.99 \pm 59.92$ & $99.78 \pm 52.86$ & 0.0341 \\
\hline LDL-cholesterol (mg/dl) & $113.41 \pm 26.50$ & $127.29 \pm 28.28$ & 0.0032 \\
\hline LDL-C/HDL-C & $2.70 \pm 2.26$ & $2.50 \pm 0.84$ & 0.522 \\
\hline Hypertension n (\%) & $87(65.9)$ & $18(32.7)$ & $<0.001$ \\
\hline CHD n (\%) & $36(27.3)$ & 0 & - \\
\hline
\end{tabular}

Data are $n, \%$, means \pm DS

eGFR, estimated glomerular filtration rate

HOMA-IR: homeostatic model assessment

Diabetic nephropathy:EGFR $<60 \mathrm{ml} / \mathrm{min}$ and/or albuminuria 


\begin{tabular}{|llll|}
\hline & $\begin{array}{l}\text { T2DM } \\
\text { women }\end{array}$ & $\begin{array}{l}\text { Control } \\
\text { women }\end{array}$ & P \\
\hline Stroke/TIA & 0 & - & - \\
\hline Carotid atherosclerosis (\%) & $34(25.7)$ & - & - \\
\hline Lower limb atherosclerosis (\%) & $24(18.2)$ & - & - \\
\hline Diabetic nephropathy $\mathrm{n}(\%)$ & $35(26.5)$ & - & - \\
\hline Diabetic retinopathy $\mathrm{n}(\%)$ & $30(22.7)$ & - & - \\
\hline Diabetic neuropathy $\mathrm{n}(\%)$ & $9(6.8)$ & - & - \\
\hline Insulin treatment $\mathrm{n}(\%)$ & $11(8.3)$ & - & \\
\hline Oral Hypoglycaemic drugs $\mathrm{n}(\%)$ & $109(82.6)$ & - & \\
\hline Data are $\mathrm{n}, \%$, means \pm DS & & & \\
\hline eGFR, estimated glomerular filtration rate & & \\
\hline HOMA-IR: homeostatic model assessment & \\
\hline Diabetic nephropathy:EGFR $<60$ ml/min and/or albuminuria & \\
\hline
\end{tabular}

T2DM women (mean duration 7.7 years; $\mathrm{HbA1c} 7.44 \%$ ), showed higher values of BMI, waist circumference, triglycerides, systolic and diastolic blood pressure, and an higher degree of insulinresistance as evaluated by HOMA-IR and hypertension rate when compared to controls $(P<0.01$ for all comparisons) (Table 1). Conversely, control women showed higher levels of total- and HDL-cholesterol ( $P$ $=0.0016$ and $P=0.010$, respectively). Overall, renal function was acceptable and comparable between the two groups.

Among T2DM women, 27\% had established CHD, 22.7\% had retinopathy, 6.8 neuropathy, 35 (26.5\%) nephropathy (eGFR $<60 \mathrm{ml} / \mathrm{min}$ and/ or albuminuria $>30 \mathrm{mg} / 24 \mathrm{~h}$ ), $25 \%$ carotid atherosclerosis and $18.2 \%$ lower limb disease. Overall, $82.6 \%$ were on oral agents and $8.3 \%$ on insulin therapy with or without oral agents (Table 1). None of controls had a history of cardiovascular disease or diabetes complications.

Circulating levels of adipokines and inflammatory markers in control, T2DM women and T2DM women with CHD are shown in Table 2. Resistin, IL-6, sVCAM, tHcy as well as folate and vitamin B12 serum levels were comparable between the T2DM and control groups, whereas hsPCR levels were $\sim 2$ times higher in T2DM than in non T2DM women $(P=0.0132)$. 
Table 2

- Resistin levels and inflammatory and endothelial markers in T2DM and control women participating to the study.

\begin{tabular}{|c|c|c|c|c|c|c|}
\hline & $\begin{array}{l}\text { Control } \\
\text { women }\end{array}$ & $\begin{array}{l}\text { All T2DM } \\
\text { women }\end{array}$ & $\begin{array}{l}\text { T2DM } \\
\text { women } \\
\text { with CHD }\end{array}$ & P1 & $\mathrm{P} 2$ & $\begin{array}{l}\text { Age- } \\
\text { adjusted P2 }\end{array}$ \\
\hline $\mathrm{n}$ & 55 & 132 & 36 & & & \\
\hline $\operatorname{Resistin}(\mathrm{ng} / \mathrm{ml})$ & $10.31 \pm 4.28$ & $10.27 \pm 4.11$ & $12.43 \pm 5.21$ & 0.953 & $\begin{array}{l}<.001 \\
0\end{array}$ & 0.013 \\
\hline hsPCR (mg/L) & $2.97 \pm 3.27$ & $5.54 \pm 6.42$ & $4.90 \pm 4.55$ & 0.0132 & 0.452 & 0.682 \\
\hline IL-6 (pg/ml) & $2.17 \pm 2.07$ & $2.87 \pm 2.07$ & $3.35 \pm 2.03$ & 0.109 & 0.317 & 0.913 \\
\hline $\begin{array}{l}\text { sVCAM1 } \\
\text { (ng/ml) }\end{array}$ & $\begin{array}{l}715.07 \pm \\
202.63\end{array}$ & $\begin{array}{l}768.65 \pm \\
313.48\end{array}$ & $\begin{array}{l}940.11 \pm \\
481.97\end{array}$ & 0.245 & $\begin{array}{l}< \\
0.001\end{array}$ & 0.118 \\
\hline $\mathrm{tHcy}(\mu \mathrm{mol} / \mathrm{L})$ & $11.47 \pm 4.58$ & $12.77 \pm 5.94$ & $15.92 \pm 7.25$ & 0.165 & $\dot{0} 001$ & 0.799 \\
\hline \multicolumn{7}{|c|}{ Data are $n$, means $\pm D S$} \\
\hline \multicolumn{7}{|c|}{$\mathrm{P} 1$ : $\mathrm{P}$ value for the comparison between T2DM and control women participating to the study } \\
\hline \multicolumn{7}{|c|}{$\mathrm{P}$ 2: $\mathrm{P}$ value for the comparison between T2DM women with and without $\mathrm{CHD}$} \\
\hline
\end{tabular}

tHcy, resistin and sVCAM levels were significantly higher in T2DM women with CHD compared to those without $(P<0.001$, all), and this difference was still significant for resistin after age-adjustment (Table 2).

T2DM women with CHD were older $(P<0.001)$, with a longer diabetes duration $(P=0.002)$ when compared to T2DM women without established CHD (Supplemental Table 1), whereas the degree of adiposity (BMI and waist circumference values), HbA1c values and lipid profile were comparable between the two groups. Micro- and macrovascular complications, and subjects on insulin treatment were also more frequent in the CHD group than in the non-CHD group $(P<0.05$ and $P<0.001$, respectively;

\section{Supplemental table 1).}

\section{Univariate and multivariate associations of resistin levels with study parameters}

Significant correlations were noted between resistin levels and all the investigated inflammatory and endothelial dysfunction markers, although the strength of the association was greater for IL-6 and sVCAM (Fig. 1).

Univariate regression analysis of resistin levels with study variables in T2DM is shown in Table 3. Overall, resistin levels were positively associated with age, hypertension, waist circumference, insulin levels and the degree of insulin resistance $\left(\mathrm{HOMA}_{\mathbb{R}}\right)$, triglycerides and creatinine levels, and inversely with $\mathrm{HDL}-\mathrm{C}$ 
concentrations (Table 3). Creatinine and hypertension showed the strongest association with resistin levels. Significant univariate associations were also noted with tHcy, IL-6, hsCRP and sVCAM (Table 3).

Table 3

Factors independently associated with Resistin levels in T2D women

\begin{tabular}{|c|c|c|c|c|c|c|}
\hline & \multicolumn{3}{|c|}{ Univariate regression analysis } & \multicolumn{3}{|c|}{ Multivariate regression analysis } \\
\hline & B & $\mathrm{P}$ & $\mathrm{OR}(95 \% \mathrm{Cl})$ & B & $\mathrm{P}$ & OR $(95 \% \mathrm{Cl})$ \\
\hline Age & 0.060 & 0.035 & $0.004-0.116$ & & & \\
\hline Diabetes duration & 0.026 & 0.563 & $-0.062-0.113$ & & & \\
\hline Hypertension & 1.851 & 0.013 & $0.389-3.314$ & & & \\
\hline BMI & 0.097 & 0.093 & $-0.016-0.211$ & & & \\
\hline Waist circumference & 0.076 & 0.015 & $0.015-0.136$ & & & \\
\hline Systolic Blood Pressure & 0.038 & 0.065 & $-0.002-0.079$ & & & \\
\hline Diastolic Blood Pressure & 0.055 & 0.171 & $-0.024-0.133$ & & & \\
\hline $\mathrm{HbA} 1 \mathrm{c}$ & 0.119 & 0.648 & $-0.394-0.632$ & & & \\
\hline Fasting glucose & 0.007 & 0.347 & $-0.007-0.021$ & & & \\
\hline Insulin levels & 0.071 & 0.033 & $0.006-0.137$ & & & \\
\hline HOMA-Index & 0.117 & 0.063 & $-0.006-0.240$ & & & \\
\hline Creatinine & 6.124 & 0.001 & $2.729-9.518$ & 5.95 & 0.005 & $1.888-10.013$ \\
\hline tHcy & 0.162 & 0.009 & $0.042-0.281$ & & & \\
\hline Total cholesterol & -0.020 & 0.099 & $-0.044-0.004$ & & & \\
\hline HDL-cholesterol & -0.055 & 0.036 & $-0.106-0.004$ & & & \\
\hline LDL-cholesterol & -0.022 & 0.079 & $-0.046-0.003$ & & & \\
\hline Triglycerides & 0.012 & 0.025 & $0.002-0.22$ & 0.02 & 0.005 & $0.006-0.034$ \\
\hline hsCRP & 0.135 & 0.006 & $0.039-0.232$ & 0.152 & 0.005 & $0.047-0.258$ \\
\hline sVCAM & 0.005 & $<0.001$ & $0.003-0.007$ & 0.003 & 0.009 & $0.001-0.006$ \\
\hline IL-6 & 0.391 & 0.002 & $0.150-0.632$ & 0.322 & 0.045 & $-0.085-0.729$ \\
\hline
\end{tabular}

At multivariate analysis, creatinine, TG, hsCRP, IL-6, and sVCAM were independently associated with resistin concentrations in T2DM women. 


\section{Factors Associated With Chd In T2dm Women}

At stepwise regression analysis, resistin levels were independently associated with $\mathrm{CHD}$, after taking into account a large set of potential confounders, including age, renal function, BMI, waist circumference, glucose control, blood pressure, lipid profile, inflammatory and endothelial dysfunction markers. Age, tHcy, LDL-C levels and hypertension were also independently associated with the occurrence of CHD in T2DM women participating to the study (Table 4).

\section{Discussion}

We investigated resistin concentration and its potential associations with CVD risk factors, as well as with inflammation and endothelial dysfunction markers in a group of outpatient obese post-menopausal women.

We found that circulating levels of resistin were similar in T2DM and non-diabetic women, whereas they were significantly higher in T2DM women with CHD.

$\mathrm{CHD}$ is a multifactorial disease, but the relative impact of risk factors may differ according to gender $(5,6$, $30,37)$.

Among these factors, obesity has been demonstrated to confer a higher cardiovascular and mortality risk in T2DM women than in men $(6,9,10)$. Adipose tissue is an active endocrine organ releasing several adipokines and inflammatory factors, including adiponectin, leptin, resistin, chemotactic protein 1 (MCP1), TNF- $a, I L-6, I L-1 \beta, I L-10$, and transforming growth factor (TGF)- $\beta$, which may contribute to the differential impact of obesity in the two genders.

Thus, serum leptin levels correlates positively with body fat content in either sex, but its levels are two times higher and its secretion rate is one third higher in women than in men (38). Similarly, also hsCRP levels are usually higher in women than in men, whereas men have higher levels of IL-6, II-8, and TNF-a (39).

To date, data on potential gender differences in resistin levels, and specifically in T2DM women are sparse. It has been reported that the association between resistin and obesity is stronger in women than in men (40), although opposite results were reported in other studies (41). Thus, a recent study on 92 T2DM subjects reported no significant difference in resistin levels according to gender and BMI, while gender- and BMI-related differences emerged for leptin, adiponectin and visfatin levels (24).

In our study, women with CHD were older than those without it, but the association of resistin levels with $\mathrm{CHD}$ risk remained significant after adjustment for age and other potential major confounders, including renal function.

Post-menopausal women with and without T2DM participating to the study were comparable for renal function, which is an important factor potentially influencing resistin concentrations $(42,43)$. Thus, also in 
our series resistin levels were strongly associated with renal function, and creatinine levels were significant predictors of resistin concentration after multiple adjustment at regression analysis. Accordingly, Moreno et al. reported that renal function strongly influenced resistin levels in a large cohort of T2DM subjects, although the association was stronger in men than in women (44).

Conversely, resistin levels were not associated to BMI in our study. Similar to our data, resistin levels have been reported to be not significantly different accoding to BMI in a recent study (24). Similarly, Hansen et al. (25) did not find any difference in resistin level in obese and non-obese T2DM subjects. As in our series, other Authors failed to find any difference in resistin levels according to the presence of T2DM and/or obesity $(26,27,45)$, whereas other recent studies only found minor differences $(46)$.

On the contrary, Mabrouk et al. showed significantly higher resistin concentration in obese diabetics vs. obese non-diabetic subjects, as well as increased resistin level in obese diabetics and non-diabetics vs. slim healthy persons (47). Observed discrepancies may depend upon several factors, including whether or not adipose tissue is dysfunctional. Beyond the role of renal function as a major determinant of resistin levels in our as well as in other studies, our hypothesis is that in our cohort, resistin levels are similar in women with and without T2DM, because of a similar degree of dysfunctional obesity, which is not captured by BMI values. In women with CHD, the higher degree of chronic inflammation and endothelial dysfunction is likely linked to the higher resistin levels.

Moreover, our data showed that resistin levels correlated with inflammatory and endothelial dysfunction markers in T2DM women, suggesting that the association of resistin with CHD risk may be mediated by the inflammatory process. A huge amount of literature has established the link of systemic inflammation, T2DM and CVD risk, although these evidences failed to be translated in clinical recommendation so far.

Our data are in accordance with several studies showing that resistin plays a major regulatory role in the inflammatory response $(48,49)$. Resistin has also been reported to upregulate the expression of proinflammatory cytokines such as TNF-a, IL-6, IL-12, and monocyte chemoattractant protein in PBMCs, macrophages, and hepatic stellate cells via the nuclear factor-kB pathway $(47,50)$; the correlation of resistin levels with inflammatory and fibrinolytic markers has been reported both in the general population and in individuals with T2DM, coronary atherosclerosis, chronic kidney disease, rheumatoid arthritis, and/or sepsis $(48,49,51)$.

A recent study conducted in subjects with and without ventricular dysfunction showed resistin levels were overall comparable to that of our study, and correlated with IL-6 and HDL/TG, but not with renal function as in our study. The youger mean age of participants (50) may partly explain the observed differences with our study

Subclinical inflammation is one of the underlying pathophysiological mechanisms linking obesity to insulin resistance, and in our study, resistin levels also correlated with the degree of insulin resistance, as assessed by $\mathrm{HOMA}_{\mathrm{IR}}$, and with all the components of the metabolic syndrome (waist circumference, hypertension, HDL-C/Ttriglycerides levels), although the association remained significant only for TG at 
multivariate analysis. Chedraui et al. demonstrated that post-menopausal women with metabolic syndrome displayed significantly higher levels of resistin, together with higher leptin and insulin levels, differences mainly observed among women with abdominal obesity, as in our cohort (52). A recent systematic literature review and meta-analysis, including fifteen studies found that resistin levels were weakly correlated with insulin resistance in T2DM and obesity, but this association was stronger in subjects with hyperresistinemia ( $\geq 14.8 \mathrm{ng} / \mathrm{ml}$ ) (53). In our study, resistin mean values were below that cut-off, and the association with HOMA IR was weak and disappeared at multivariate analysis.

Furthermore, significant associations were shown between resistin and tHcy and sVCAM levels, that were all comparable in T2DM women and controls, but increased in T2DM women with CHD. Human resistin may play an important regulatory role in the modulation of the interaction between endothelial cells, monocytes/macrophages, and VSMC in the pathogenesis and progression of atherosclerosis, as demonstrated in several experimental $(54,55)$, and clinical studies $(56)$.

In our study, resistin was also independently associated with a higher CHD risk in T2DM women, after taking into account a large set of covariates.

A causal- effect relationship cannot be ascertained from our data, and for other inflammatory and not conventional CVD risk factors, it is overall difficult to establish whether these molecules are directly responsible for the atherosclerotic damage or their circulating levels are only markers of the underlining pathophysiological process.

In a cohort of 284 T2D patients (48\% females), followed-up for 5.4 years, higher resistin levels were associated with reduced survival, and resistin concentration $\geq 11 \mathrm{ng} / \mathrm{mL}$ was an indicator of unfavorable outcomes (57), a cut-off exceeded in CHD women in our cohort. Several other studies reported high levels of resisitin in patients with established CVD, including myocardial infarction, recurrent ischemic events, and overall with CVD complications $(48,55)$. These data are in line with our results and point to a potential pathophysiological relationship of resistin with CVD risk in obese T2DM women.

Several limitations should be acknowledged when interpreting our results. The first deals with the cross sectional study design and the relatively small number of subjects included in this analysis. However, several important confounding factors including lipid profile and major inflammatory and endothelial dysfunction markers were considered in our analysis.

The lack of data on genetic variants on human Retn gene, that have been correlated with Retn expression and resistin levels in metabolic disorders, including T2DM and obesity (58) is another potential limitation.

\section{Conclusions}

In summary, our data show that circulating resistin levels are comparable in overweight/obese postmenopause women with and without T2DM, but they are independent predictors of CHD risk in this 
cohort. Furthermore, resistin levels were associated with renal function, and with atherogenic lipid, inflammatory and endothelial dysfunction factors.

There is an urgent need to define gender-specific CVD risk factors in T2DM, and our data add a piece of information on the debated role of resistin in this field.

\section{Abbreviations}

\section{T2DM}

Type 2 diabetes mellitus

$\mathrm{CHD}$

coronary heart disease

sVCAM

Soluble vascular cell adhesion molecule-1

tHcy

homocysteine

hsPCR

high-sensitivity C-reactive protein

CVD

Cardiovascular disease

\section{Declarations}

Ethics approval and consent to participate: The study was approved by the local Ethics Committee (Comitato Etico Scientifico Interaziendale di Messina, Italy).

Consent: A written consent was obtained from all subjects participating in this study, who were informed about all aspects of the study .

Funding: The authors didn't receive any specific funding for this work.

Competing interests: The authors declare that they have no competing interests.

Availability of data and materials: The data that support the findings of this study are available from the corresponding author, upon reasonable request.

Acknowledgements: 'Not applicable'

\section{Author's contribution:}

Annalisa Giandalia and Giuseppina T. Russo originated the proposal, extracted data, and prepared the report for publication. 
Letterio Giorgianni, Giorgio E. Longo, Federico Lo Piano and Francesca Consolo were members of the research team and reviewed a draft of the report.

Angela Alibrandi was a member of the research team and provided statistical analysis

Bela Asztalos, Domenico Cucinotta and Giovanni Squadrito contributed to the early drafts of the paper and reviewed the manuscript.

\section{References}

1. Russo GT. Giorda CB. Cercone S. Nicolucci A. Cucinotta D; BetaDecline Study Group. Factors associated with beta-cell dysfunction in type 2 diabetes: the BETADECLINE study. PLoS One. 2014 Oct 27;9(10):e109702. doi: 10.1371/journal.pone.0109702

2. Russo GT. Baggio G. Rossi MC. Kautzky-Willer A. Type 2 diabetes and cardiovascular risk in women. Int J Endocrinol. 2015;2015:832484. doi:10.1155/2015/832484.

3. Mulnier HE. Seaman HE. Raleigh VS. Soedamah-Muthu SS. Colhoun HM. Lawrenson RA. De Vries CS. Risk of stroke in people with type 2 diabetes in the UK: a study using the General Practice Research Database. Diabetologia. 2006 Dec;49(12):2859-65.

4. Russo GT, Giandalia A, Romeo EL, Muscianisi M, Ruffo MC, Alibrandi A, Bitto A, Forte F, Grillone A, Asztalos B, Cucinotta D. HDL subclasses and the common CETP TaqIB variant predict the incidence of microangiopatic complications in type 2 diabetic women: A 9years follow-up study. Diabetes Res Clin Pract. 2017 Oct;132:108-117. doi: 10.1016/j.diabres.2017.07.026. Epub 2017 Jul 28.PMID: 28829977

5. Russo GT. Giandalia A. Romeo EL. Marotta M. Alibrandi A. De Francesco C. Horvath KV. Asztalos B. Cucinotta D. Lipid and non-lipid cardiovascular risk factors in postmenopausal type 2 diabetic women with and without coronary heart disease. J Endocrinol Invest. 2014 Mar;37(3):261-8.

6. Avogaro A, Giorda C, Maggini M, Mannucci E, Raschetti R, Lombardo F, Spila-Alegiani S, Turco S, Velussi M, Ferrannini E; Diabetes and Informatics Study Group, Association of Clinical Diabetologists, Istituto Superiore di Sanità. Incidence of coronary heart disease in type 2 diabetic men and women: impact of microvascular complications. treatment. and geographic location.Diabetes Care. 2007 May;30(5):1241-7.

7. Russo G, Pintaudi B, Giorda C, Lucisano G, Nicolucci A, Cristofaro MR, Suraci C, Mulas MF, Napoli A, Rossi MC, Manicardi V. Age- and Gender-Related Differences in LDL-Cholesterol Management in Outpatients with Type 2 Diabetes Mellitus. Int J Endocrinol. 2015;2015:957105. doi: 10.1155/2015/957105. Epub 2015 Mar 19. PMID: 25873960; PMCID: PMC4383267.

8. Zaccardi F. Dhalwani NN. Papamargaritis D. Webb DR. Murphy GJ. Davies MJ. Khunti K. Nonlinear association of BMI with all-cause and cardiovascular mortality in type 2 diabetes mellitus: a systematic review and meta-analysis of 414.587 participants in prospective studies. Diabetologia. 2017 Feb;60(2):240-248. 
9. Kautzky-Willer A. Baggio G. Rossi MC. Lapolla A. Russo GT. Type 2 Diabetes and Cardiovascular Risk in Women 2016. Int J Endocrinol. 2017;2017:6905697. doi:10.1155/2017/6905697

10. Kautzky-Willer A. Harreiter J. Pacini G. Sex and Gender Differences in Risk, Pathophysiology and Complications of Type 2 Diabetes Mellitus. Endocr Rev. 2016 Jun;37(3):278-316

11. Spiegelman BM. Flier JS. (2000) Obesity and the regulation of energy balance. Cell 104: 240 531543. 241

12. Halaas JL. Gajiwala KS. Maffei M. et al. (1995) Weight-reducing effects of the plasma protein 242 encoded by the obese gene. Science 269: 543-546. 243 94: 8878-8883

13. Steppan CM. Bailey ST. Bhat S. Brown EJ. Banerjee RR. Wright CM. Patel HR. Ahima RS. Lazar MA. The hormone resistin links obesity to diabetes. Nature. 2001; 409:307-312

14. Lazar MA. Resistin- and Obesity-associated metabolic diseases. Horm Metab Res. 2007; 39:710-716

15. Satoh H. Nguyen MT. Miles PD. Imamura T. Usui I. Olefsky JM. Adenovirus-mediated chronic "hyperresistinemia" leads to in vivo insulin resistance in normal rats. J Clin Invest. 2004; 114:224-231

16. Rajala MW. Obici S. Scherer PE. Rossetti L. Adipose-derived resistin and gut-derived resistin-like molecule-beta selectively impair insulin action on glucose production. J Clin Invest. 2003; 111:225230.

17. Banerjee RR. Rangwala SM. Shapiro JS. Rich AS. Rhoades B. Qi Y. Wang J. Rajala MW. Pocai A. Scherer PE. Steppan CM. Ahima RS. Obici S. et al. Regulation of fasted blood glucose by resistin. Science. 2004; 303:1195-1198.

18. Muse ED. Obici S. Bhanot S. Monia BP. McKay RA. Rajala MW. Scherer PE. Rossetti L. Role of resistin in diet-induced hepatic insulin resistance. J Clin Invest. 2004; 114:232-239.

19. Bo S. Gambino R. Gentile L. Pagano G. Rosato R. Saracco GM. Cassader M. Durazzo M. CavalloPerin P. High-normal blood pressure is associated with a cluster of cardiovascular and metabolic risk factors: a population-based study. J Hypertens. 2009; 27:102-108.

20. Ntaios G. Gatselis NK. Makaritsis K. Dalekos GN. Adipokines as mediators of endothelial function and atherosclerosis. Atherosclerosis. 2013; 227:216-221

21. Burnett MS. Lee CW. Kinnaird TD. Stabile E. Durrani S. Dullum MK. Devaney JM. Fishman C. Stamou S. Canos D. Zbinden S. Clavijo LC. Jang GJ. et al. The potential role of resistin in atherogenesis. Atherosclerosis. 2005; 182:241-248

22. Muse ED, Feldman DI. Blaha MJ, Dardari ZA, Blumenthal RS, Budoff MJ, Nasir K, Criqui $\mathrm{MH}$, Cushman M, McClelland RL, Allison MA. The association of resistin with cardiovascular disease in the Multi-Ethnic Study of Atherosclerosis. Atherosclerosis. 2015; 239:101-108

23. Yuxiang Zhang et al. Association between serum resistin concentration and hypertension: A systematic review and meta-analysis. Oncotarget. 2017. Vol. 8. (No. 25). pp: 41529-41537

24. Kocot J, Dziemidok P, Kiełczykowska M, Hordyjewska A, Szcześniak G, Musik I. Adipokine Profile in Patients with Type 2 Diabetes Depends on Degree of Obesity. Med Sci Monit. 2017 Oct 19;23:49955004. doi: 10.12659/msm.904318. PMID: 29049270; PMCID: PMC5659140. 
25. Hansen $D$, Dendale $P$, Beelen $M$ et al: Plasma adipokine and inflammatory marker concentrations are altered in obese, as opposed to non-obese, type 2 diabetes patients. Eur J Appl Physiol, 2010; 109(3): 397-404

26. AL-Suhaimi EA, AL-Kulaifi F, Shehzad A: Serum adipokines metabolic function and immunological correlations in treated type 2 diabetes mellitus and obese subjects. World Applied Sciences Journal, 2013; 22(7): 933-38

27. Mohammadzadeh G, Zarghami N, Mobaseri M: Serum resistin concentration in obese diabetic patients: Any possible relation to insulin resistance indices? Int J Endocrinol Metab, 2008; 4: 183-93

28. G.M. Pine, H.M. Batugedara, M.G. Nair. Here, there and everywhere: Resistin-like molecules in infection, inflammation, and metabolic disorders. Cytokine, 110 (2018), pp. 442-451.

29. Patel L. Buckels AC. Kinghorn IJ. Murdock PR. Holbrook JD. Plumpton C. Macphee CH. Smith SA. Resistin is expressed in human macrophages and directly regulated by PPAR gamma activators. Biochem Biophys Res Commun. 2003; 300:472-476

30. Penno G, Solini A, Bonora E, Fondelli C, Orsi E, Zerbini G, Trevisan R, Vedovato M, Gruden G, Laviola L, Nicolucci A, Pugliese G; Renal Insufficiency And Cardiovascular Events (RIACE) study, group. Gender differences in cardiovascular disease risk factors, treatments and complications in patients with type 2 diabetes: the RIACE Italian multicentre study. J Intern Med. 2013 Aug; 274(2):176-91. doi: 10.1111/joim.12073. Epub 2013 Apr 22.

31. Rossi MC, Lucisano G, Pintaudi B, Bulotta A, Gentile S, Scardapane M, Skovlund SE, Vespasiani G, Nicolucci A; BENCH-D Study Group. The complex interplay between clinical and personcentered diabetes outcomes in the two genders. Health Qual Life Outcomes. 2017 Feb 21;15(1):41. doi: 10.1186/s12955-017-0613-0.PMID: 28222781

32. De Luis DA, Gonzalez Sagrado M, Conde R, Aller R, Izaola O, Perez Castrillon JL, Dueñas A. Relation of resistin levels with cardiovascular risk factors and insulin resistance in non-diabetes obese patients. Diabetes Res Clin Pract. 2009 May;84(2):174-8.).

33. Classification and diagnosis of diabetes: standards of medical care in diabetes-2020. American Diabetes Association. Diabetes Care. 2020;43:14-31.

34. Whelton PK, Carey RM, Aronow WS, Casey DE Jr., Collins KJ, Dennison Himmelfarb C, DePalma SM, Gidding S, Jamerson KA, Jones DW, MacLaughlin EJ, Muntner P, Ovbiagele B, Smith SC Jr., Spencer CC, Stafford RS, Taler SJ, Thomas RJ, Williams KA Sr., Williamson JD, Wright JT Jr. : 2017 ACC/AHA/AAPA/ABC/ACPM/AGS/APhA/ASH/ASPC/NMA/PCNa guideline for the prevention, detection, evaluation, and management of high blood pressure in adults: A report of the American College of Cardiology/American Heart Association Task Force on clinical practice guidelines. J Am Coll Cardiol 71: 2199-2269, 2018.

35. Levey AS, Stevens LA, Schmid CH, Zhang YL, Castro AF 3rd, Feldman HI, Kusek JW, Eggers P, Van Lente F, Greene T, Coresh J; CKD-EPI (Chronic Kidney Disease Epidemiology Collaboration). A new equation to estimate glomerular filtration rate. Ann Intern Med. 2009 May 5;150(9):604-12. doi: 10.7326/0003-4819-150-9-200905050-00006. 
36. Standard italiani per la cura del diabete Mellito 2018, AMD-SID. https://www.siditalia.it/clinica/standard-di-cura-amd-sid

37. Russo GT, Giandalia A, Romeo EL, Alibrandi A, Horvath KV, Asztalos BF, Cucinotta D. Markers of Systemic Inflammation and Apo-Al Containing HDL Subpopulations in Women with and without Diabetes. Int J Endocrinol. 2014;2014:607924. doi: 10.1155/2014/607924. Epub 2014 Sep .PMID: 25258627

38. Hellström L, Wahrenberg H, Hruska K, Reynisdottir S, Arner P. Mechanisms behind gender differences in circulating leptin levels. J Intern Med. 2000Apr;247(4):457-62

39. Amélie Cartier, Mélanie Côté, Isabelle Lemieux, Louis Pérusse, Angelo Tremblay, Claude Bouchard, Jean-Pierre Després Sex differences in inflammatory markers: what is the contribution of visceral adiposity? The American Journal of Clinical Nutrition, Volume 89, Issue 5, May 2009, Pages 13071314

40. de Luis DA, Gonzalez Sagrado M, Conde R, Aller R, Izaola O, Perez Castrillon JL, Dueñas A. Relation of resistin levels with cardiovascular risk factors and insulin resistance in non-diabetes obese patients. Diabetes Res Clin Pract. 2009 May;84(2):174-8. doi: 10.1016/j.diabres.2009.01.017. Epub 2009 Feb 24

41. Hansen D, Dendale P, Beelen M, Jonkers RA, Mullens A, Corluy L, Meeusen R, van Loon LJ. Plasma adipokine and inflammatory marker concentrations are altered in obese, as opposed to non-obese, type 2 diabetes patients. Eur J Appl Physiol. 2010 Jun;109(3):397-404. doi: 10.1007/s00421-0101362-5. Epub 2010 Feb 4. PMID: 20131064; PMCID: PMC2874484.

42. Kawamura R, Doi Y, Osawa H, Ninomiya T, Hata J, Yonemoto K, et al. Circulating resistin is increased with decreasing renal function in a general Japanese population: the Hisayama Study. Nephrol Dial Transplant. 2010;25: 3236-3240.

43. Menzaghi C, Salvemini L, Fini G, Thompson R, Mangiacotti D, Di Paola R, Morini E, Giorelli M, De Bonis C, De Cosmo S, Doria A, Trischitta V. Serum resistin and kidney function: a family-based study in non-diabetic, untreated individuals. PLoS One. 2012;7(6):e38414. doi:

10.1371/journal.pone.0038414. Epub 2012 Jun 12.PMID: 22701635

44. Moreno LO, Salvemini L, Mendonca C, Copetti M, De Bonis C, De Cosmo S, Doria A, Trischitta V, Menzaghi C. Serum resistin and glomerular filtration rate in patients with type 2 diabetes. PLoS One. 2015 Mar 26; 10(3):e0119529. doi: 10.1371/journal.pone.0119529. eCollection 2015.PMID: 25811174

45. Yaturu S, Daberry RP, Rains J, Jain S: Resistin and adiponectin levels in subjects with coronary artery disease and type 2 diabetes. Cytokine, 2006; 34: 219-23

46. Al Sheikh MH: The determinants of leptin levels in diabetic and nondiabetic Saudi Males. Int J Endocrinol, 2017; 2017: 3506871

47. Mabrouk R, Ghareeb H, Shehab A et al: Serum visfatin, resistin and IL-18 in A group of Egyptian obese diabetic and non diabetic individuals. Egypt J Immunol, 2013; 20(1): 1-11 
48. Filkova M, Haluzik M, Gay S, Senolt L. The role of resistin as a regulator of inflammation: Implications for various human pathologies. Clin Immunol 2009; 133:157-170.

49. Jamaluddin MS, Weakley SM, Yao Q, Chen C. Resistin: functional roles and therapeutic considerations for cardiovascular disease. Br J Pharmacol 2012; 165:622-632.

50. Ghanem SE, Abdel-Samiee M, Torky MH,et al. Role of resistin, IL-6 and NH2-terminal portionproBNP in the pathogenesisof cardiac disease in type 2 diabetes mellitus.BMJ Open Diab Res Care2020;8:e001206. doi:10.1136/ bmjdrc-2020-001206

51. Su K, Li Y, Zhang D, Yuan J, Zhang C,Liu Y, Song L, Lin Q, Li M and Dong J(2019) Relation of Circulating Resistin to Insulin Resistance in Type 2 Diabetes and Obesity: A SystematicReview and Meta-Analysis.Front. Physiol. 10:1399.doi: 10.3389/fphys.2019.01399

52. Chedraui P, Pérez-López FR Escobar GS, Palla G, Montt-Guevara M, Cecchi E, Genazzani AR, Simoncini T; Research Group for the Omega Women's Health Project. Circulating leptin, resistin, adiponectin, visfatin, adipsin and ghrelin levels and insulin resistance in postmeopausal women with and without the metabolic syndrome Maturitas. 2014 Sep;79(1):86-90

53. Su KZ, Li YR, Zhang D, Yuan JH, Zhang CS, Liu Y, Song LM, Lin Q, Li MW, Dong J. Relation of Circulating Resistin to Insulin Resistance in Type 2 Diabetes and Obesity: A Systematic Review and Meta-Analysis. Front Physiol. 2019 Nov 19;10:1399. doi: 10.3389/fphys.2019.01399. PMID: 31803062; PMCID: PMC6877503.

54. Manduteanu I, Pirvulescu M, Gan AM, et al. Similar effects of resistin and high glucose on P-selectin and fractalkine expression and monocyte adhesion in human endothelial cells. Biochem Biophys Res Commun 2010;391:1443-1448.

55. Jamaluddin MS, Yan S, Lu J, Liang Z, Yao Q, Chen C. Resistin increases monolayer permeability of human coronary artery endothelial cells. PLoS One 2013; 8:e84576

56. Yang et al. Circulating levels of adipose tissue-derived inflammatory factors in elderly diabetes patients with carotid atherosclerosis: a retrospective study Cardiovasc Diabetol (2018) 17:75

57. Kapłon-Cieślicka A, Tymińska A, Rosiak M, Ozierański K, Peller , Eyileten C, Kondracka , APordzikJ , Mirowska-Guzel D, Opolski G, Postuła M, Filipiak KJ. Resistin is a prognostic factor for death in type 2 diabetes Diabetes Metab Res Rev. 2019 Feb; 35(2):e3098. doi: 10.1002/dmrr.3098. Epub 2018 Dec 13

58. Pine GM, Batugedara HM, Nair MG. Here, There and Everywhere: Resistin-like Molecules in Infection, Inflammation, and Metabolic Disorders. Cytokine. 2018 October; 110: 442-451

\section{Figures}



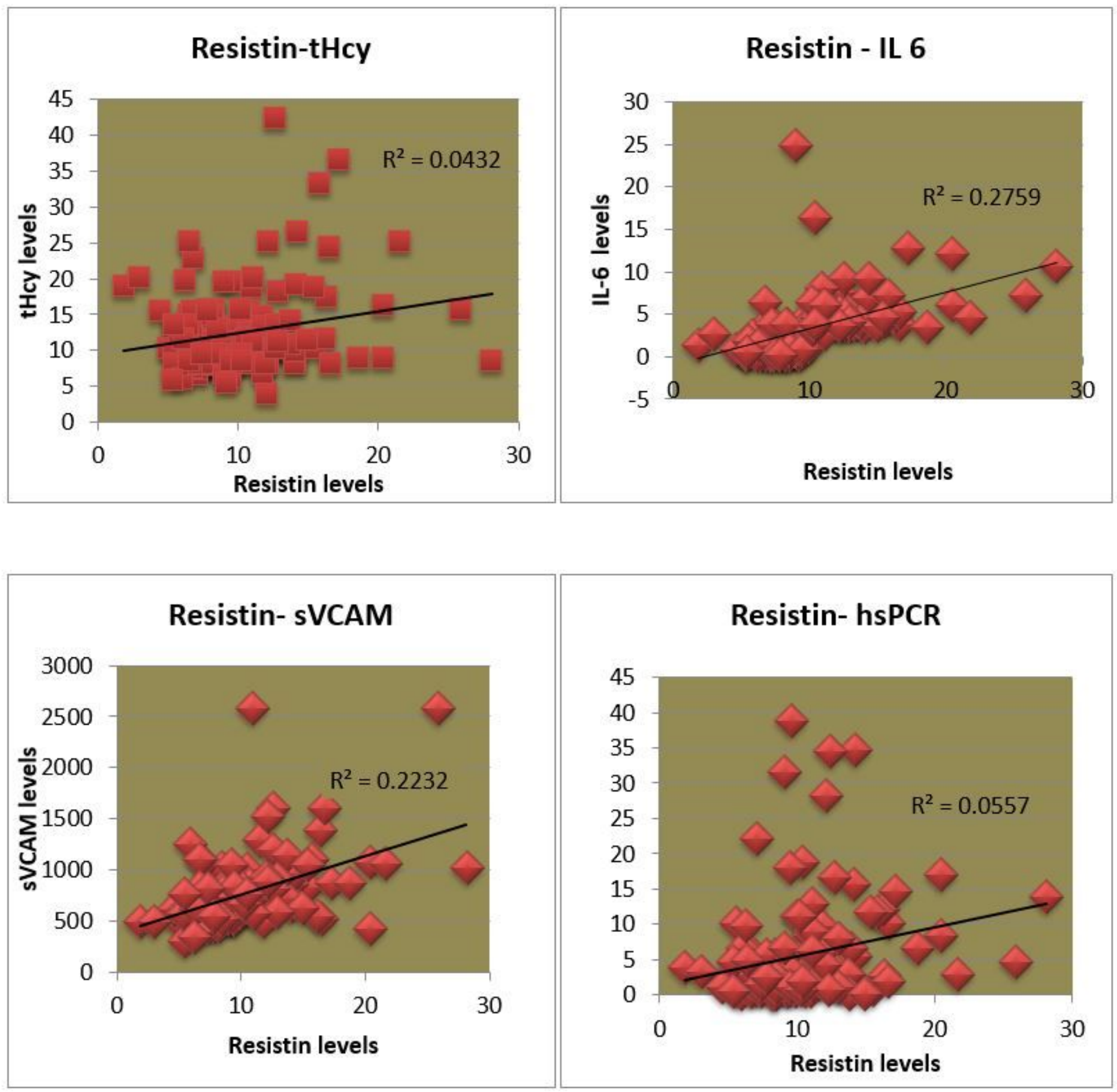

Figure 1

Correlations of resistin levels with inflammatory and endothelial dysfunction markers in T2DM women

\section{Supplementary Files}

This is a list of supplementary files associated with this preprint. Click to download.

- SupplementalTable1.docx 